UMR 5824

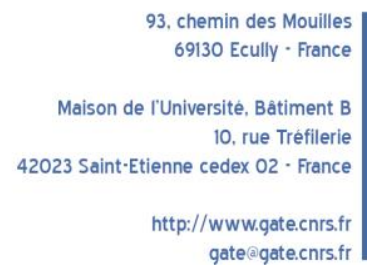

WP 1803 - February 2018

\title{
Expectation-driven asset price fluctuations under the spirit of capitalism hypothesis: The role of heterogeneity
}

\author{
Lise Clain-Chamosset-Yvrard
}

\begin{abstract}
:
In this paper, I study how heterogeneity amongst agents affects the occurrence of expectation-driven asset price fluctuations in a pure exchange economy à la Lucas, with infinitely-lived households, under the hypothesis of spirit of capitalism. I consider heterogeneous households in terms of preferences, endowments and initial wealth, and capture the spirit of capitalism through preferences for wealth. Preferences for wealth are the key element of this paper in a twofold aspect. First, they explain the occurrence of asset price fluctuations driven by self-fulfilling changes in expectations. Second, heterogeneity in endowments affects asset price level and dynamics only if preferences are heterogeneous. For instance, if agents with the strongest spirit of capitalism are also the rich in terms of endowments, heterogeneity in endowments heightens the asset price level in the long run, and destabilizes by enlarging the range of parameter values for which expectation-driven asset price fluctuations occur.
\end{abstract}

Keywords:

Asset pricing model, Spirit of Capitalism, Heterogeneity, Expectation-driven fluctuations

JEL codes:

C62, E21, E32

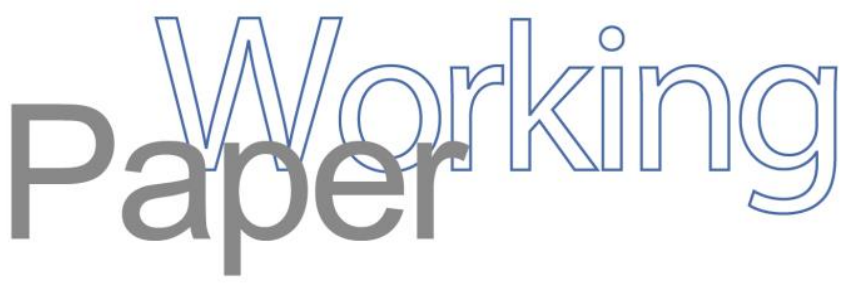




\title{
Expectation-driven asset price fluctuations under the spirit of capitalism hypothesis: The role of heterogeneity*
}

\author{
Lise Clain-Chamosset-Yvrard ${ }^{\dagger}$
}

January 5, 2018

\begin{abstract}
In this paper, I study how heterogeneity amongst agents affects the occurrence of expectation-driven asset price fluctuations in a pure exchange economy à la Lucas, with infinitely-lived households, under the hypothesis of spirit of capitalism. I consider heterogeneous households in terms of preferences, endowments and initial wealth, and capture the spirit of capitalism through preferences for wealth. Preferences for wealth are the key element of this paper in a twofold aspect. First, they explain the occurrence of asset price fluctuations driven by self-fulfilling changes in expectations. Second, heterogeneity in endowments affects asset price level and dynamics only if preferences are heterogeneous. For instance, if agents with the strongest spirit of capitalism are also the rich in terms of endowments, heterogeneity in endowments heightens the asset price level in the long run, and destabilizes by enlarging the range of parameter values for which expectation-driven asset price fluctuations occur.
\end{abstract}

JEL classification: C62, E21, E32.

Keywords: Asset pricing model, Spirit of Capitalism, Heterogeneity, Expectation-driven fluctuations.

\section{Introduction}

Since the Great Recession, which officially followed the financial crisis of 2007-2008 in the United States, topics on inequality have risen in developed countries (see among others Rajan (2010), Atkinson, Piketty and Saez (2011), Kumhof et al. (2015)). For instance, Rajan (2010) argues that a rise in inequality was the cause of the financial crisis of 2007-2008 in the United States. Furthermore, it is well-known in the finance literature that asset prices undergo an excessive volatility with regard to their underlying fundamentals as dividends (see Shiller $(1981,2015)$ ). Instead of explaining the relationship between inequality and financial crises, the question addressed in this paper is the following: What are the implications of heterogeneity amongst agents on the excessive asset price volatility?

Aim of this paper. The main purpose of this theoretical paper is to provide new insights into the role of heterogeneity, in particular in terms of preferences and endowments, on asset price

\footnotetext{
*I am grateful for useful suggestions from Nicolas Abad, Aurélien Eyquem, Takashi Kamihigashi, Cuong Le Van, Carine Nourry, Thomas Seegmuller, Alain Venditti and Bertrand Wigniolle and from participants at Dyniper Conference at Marseille. Any remaining errors are mine.

†Univ Lyon, Université Lumière Lyon 2, GATE UMR 5824, F-69130 Ecully, France. E-mail: clainchamosset@gate.cnrs.fr
} 
volatility. I attribute the excessive asset price volatility to the existence of multiple equilibria likely to occur in dynamic general equilibrium models. Therefore, fluctuations are the results of consecutive jumps from one equilibrium to another driven by self-fulfilling changes in agents' expectations without requiring any shock on fundamentals, i.e., preferences and/or technology.

Framework. In this paper, I consider an extension of the Lucas (1978) pure exchange economy. First, I introduce heterogeneity, and consider three sources of heterogeneity: preferences, initial wealth, and endowments. Second, I argue that psychological motives for savings give rise to expectation-driven fluctuations in asset prices. I focus on the spirit of capitalism (henceforth, SOC) hypothesis developed by Weber (1905), which captures the intrinsic desire for wealth accumulation. ${ }^{1}$ Following Zou $(1994,1995)$, I introduce SOC hypothesis through preferences for wealth, and consider a non-seperable utility function between consumption and wealth holdings. Several empirical studies about the saving behaviour of top income households in the United States support the existence of wealth preferences (see Carroll (2000), Dynan et al. (2004), Kumhof et al. (2015)). Moreover, some microfoundations can explain wealth preferences as underlined in Saez and Stantcheva (2016): bequests motives, services from wealth, social status. ${ }^{2}$

Results. Preferences for wealth are the key element in this paper for three reasons. First, all agents accumulate wealth in the long run, and thus hold financial assets whatever the interest rate level and their endowments. This result contrasts with neoclassical optimal growth models à la Becker (1980) with borrowing constraints and heterogeneity in discount rates. Since the interest rate is given by the most patient, only the most patient agent holds the whole financial stock in the long run in these models. ${ }^{3}$ Second, preferences for wealth also explain the occurrence of asset price fluctuations driven by self-fulfilling expectations. This result provides a theoretical evidence for the excessive asset price volatility unrelated to fundamentals observed in the data. More precisely, expectation-driven asset price fluctuations are likely to occur when wealth and consumption are Edgeworth-substitutes, i.e., when the marginal utility of consumption is decreasing with wealth. Third, investigating the role of heterogeneity, I show that heterogeneity in endowments affects asset price level and dynamics only if preferences for wealth are heterogeneous. For instance, if agents with the strongest willingness for wealth accumulation are also the rich in terms of endowments, heterogeneity in endowments heightens the asset price level in the long run, and destabilizes by enlarging the range of parameter values for

\footnotetext{
${ }^{1}$ Marx (1867), but also Keynes (1919) point out that the desire to accumulate wealth as end in itself by some agents is often the causes of financial and economic crises.

${ }^{2}$ For more details, the reader can refer to Saez and Stantcheva (2016). They devote a section for the foundations of wealth preferences.

${ }^{3}$ See Becker (2006) for a survey of the literature about neoclassical growth models with heterogeneous agents and borrowing constraints.
} 
which expectation-driven asset price fluctuations occur. This result justifies the implementation of economic policy in a stabilizing perspective, like dividend taxation or redistribution policies.

Related literature. At first, this paper relates to the literature on asset pricing in macroeconomics, and in particular to the consumption-based asset pricing models, pioneered by Stiglitz (1970), Lucas (1978) and Breeden (1979). In order to improve the performance of Lucas (1978) with observed facts in asset prices, several papers propose to consider alternative assumptions on preferences and/or to include some heterogeneity. I first discuss the literature dealing with alternative assumptions on preferences, then the literature on heterogeneity in asset pricing models. A first approach was to consider Epstein-Zin preferences to disentangle risk aversion from intertemporal substitution, while another approach was to include consumption externalities, as "keeping up with Joneses" (Gali (1994)) or external consumer habits (Campbell and Cochrane (1999)). Several theoretical studies also claim that preferences for wealth are useful for understanding asset price behaviour (see Bakshi and Chen (1996), Smith (2001), Boileau and Braeu (2007)). This paper is in line with this latter branch of the literature, and is closely related to Kamihigashi (2008) and Airaudo (2017), which highlight the role of preferences for wealth in the occurrence of expectation-driven asset price fluctuations in a representative agent framework. The main contribution of this paper with respect to Kamihigashi (2008) and Airaudo (2017) is to investigate the role of heterogeneity on the occurrence of expectation-driven asset price fluctuations when agents derive preferences for wealth.

This paper is also related to the literature about heterogeneous agents and asset pricing. A large body of the literature considers models à la Bewley (1977) or à la Aiyagari (1994). Following these models, households are ex-ante identical, but face different idiosyncratic shocks on endowments or on labour income. In this paper, households are ex-ante different with respect to their preferences, their initial wealth and their endowments. For this reason, this paper is close to Becker (1980), Kocherlakota (1992), Santos and Woodford (1997), Huang and Werner (2004), and more recently Le Van et al. (2015). In contrast, these papers consider a framework without SOC hypothesis, and deal with a different topic, which is the existence of a rational bubble.

Finally, a number of theoretical papers have stressed that non-separable utility function between consumption and money is important to generate multiple equilibria in dynamic general equilibrium models, and thus fluctuations driven by the volatility of agents' expectations (see Obstfeld (1984) and Matsuyama (1990) for an overview). As Airaudo (2017), I show that expectation-driven asset price fluctuations are likely to occur when wealth and consumption are Edgeworth-substitutes, i.e., when the marginal utility of consumption is decreasing with wealth. A similar result appears in the literature about Money-in-the-Utility-Function 
(henceforth, MIUF). Assuming a Edgeworth substitutability between consumption and money is neither empirically plausible (Walsh (2010)) nor consistent with the idea that money serves as a medium exchange. However, a negative cross-derivative between wealth and consumption is coherent with the concept of frugality at the root of SOC hypothesis developed by Weber (1905). Furthermore, it is worth pointing out that housing wealth is a large component of households' wealth (see Survey of Consumer Finances (2013) for U.S. data). Since several studies shed light on the fact that housing and consumption are Edgeworth-substitutes (see Flavin and Nakagawa (2008), Piazzesi et al. (2007) and Yogo (2006)), considering a negative cross-derivative between consumption and wealth would be compatible with empirical evidences.

Layout. Section 2 presents the model. Section 3 is devoted to the intertemporal equilibrium. In Section 4, I describe the mean-preserving method. Section 5 analyses the existence and uniqueness of the steady state. In Section 6, I study local dynamics and the occurrence of expectation-driven asset price fluctuations. Section 7 is devoted to the role of heterogeneity on the existence of asset price fluctuations. Concluding remarks are provided in Section 8, while computational details are gathered in Appendix.

\section{The model}

The starting point is a modified version of the pure exchange economy developed by Lucas (1978) with $n$ infinitely-lived heterogeneous households. ${ }^{4}$ There are three sources of heterogeneity: preferences, initial wealth, and endowments. Without loss of generality, I consider two types of households, labelled with $i=0,1$. More precisely, there are $n_{i}>1$ agents of type $i$ with $n_{0}+n_{1}=n$.

Preferences. Agents derive utility both from consumption $c_{i}(t)$ and from financial wealth $w_{i}(t)$. Preferences for wealth capture the SOC hypothesis. The utility function of an agent $i$ at time $t=0$ is the discounted sum of instantaneous utilities:

$$
\int_{0}^{+\infty} e^{-\rho t} u_{i}\left(c_{i}(t), w_{i}(t)\right) d t
$$

where $\rho>0$ is the common subjective rate of time preference.

Following Smith (2001) and Airaudo (2017), preferences of an agent $i$ are summarized by

\footnotetext{
${ }^{4}$ Since I want to focus on the role of wealth preferences and heterogeneity on asset price dynamics, I ignore physical capital accumulation.
} 
the following non-separable utility function in consumption and wealth:

$$
u_{i}\left(c_{i}(t), w_{i}(t)\right)=\left\{\begin{array}{cc}
\frac{\left[c_{i}(t)^{\alpha} w_{i}(t)^{\gamma_{i}}\right]^{1-\varepsilon}-1}{1-\varepsilon} & \text { if } \varepsilon>0, \varepsilon \neq 1 \\
\alpha \log c_{i}(t)+\gamma_{i} \log w_{i}(t) & \text { if } \varepsilon=1
\end{array}\right.
$$

where $\varepsilon>0$ and $\alpha \in(0,1)$ are respectively the inverse of the intertemporal elasticity of substitution and the weight of consumption in the utility function.

Heterogeneity in preferences. Heterogeneity in preferences is captured by the parameter $\gamma_{i}>0$, which measures the weight of wealth in the utility function, as long as $\gamma_{1} \neq \gamma_{0}$. Without loss of generality, I rule out the case in which agents do not display preferences for wealth, and consider a particular distribution for $\gamma_{i}^{5}$ :

Assumption $10<\gamma_{0} \leq \gamma_{1}$.

Under Assumption 1, agents 1 have a stronger willingness for wealth accumulation than agents 0 . To ensure the concavity of the utility function, I make the following assumption:

Assumption $21-\left(\alpha+\gamma_{i}\right)(1-\epsilon) \geq 0$.

Consumption and wealth are normal goods under this utility function. Moreover, when $\varepsilon \leq 1$, the marginal utility of consumption is increasing with wealth $\left(i . e ., u_{i c w}\left(c_{i}, w_{i}\right)>0\right.$ ), meaning that consumption and wealth are Edgeworth-complements. When $\varepsilon \geq 1$, the marginal utility of consumption is decreasing with wealth (i.e., $\left.u_{i c w}\left(c_{i}, w_{i}\right)<0\right)$, then consumption and wealth are Edgeworth-substitutes. ${ }^{6}$

Budget constraint. At the initial period $t=0$, households are endowed with different shares of the initial stock $s_{i}(0)$. At time $t$, each household $i$ receives a constant dividend $d$ per share and an exogenous endowment of $y_{i}>0$ units of final good, which can be interpreted as labour income. Each household trades and buys new shares $s_{i}(t)$ at price $q(t)$, and consumes $c_{i}(t)$ units of final good.

Heterogeneity in initial wealth. Households are also heterogeneous with respect their initial wealth. In this framework, the initial distribution of wealth does not matter at the steady

\footnotetext{
${ }^{5}$ Since Becker (1980), heterogeneity in preferences is a common assumption in infinite-horizon models with borrowing constraints, but mostly concerns the rate of time preference. Since I want to highlight the role of heterogeneity in wealth preferences on the occurrence of expectation-driven fluctuations, I ignore others forms of preference heterogeneity, i.e., in the rate of time preference, in the intertemporal elasticity of substitution and in the weight of consumption in the utility function.

${ }^{6}$ In this framework, I restrict attention to a class of utility functions which imposes a substitution elasticity between wealth and consumption equal to the unity. This functional form is quite standard in the existing literature about SOC (see Bakshi and Chen (1996), Gong and Zou (2002), Boileau and Braeu (2007)). Considering this formulation allows me to provide a clear insight into the role of preference heterogeneity on dynamics by focusing only on a single parameter, namely $\gamma_{i}$.
} 
state because of the homothetic property of the utility function. Since I am interested in the occurrence of expectation-driven fluctuations in the neighbourhood of a steady state, such a heterogeneity will not affect asset price dynamics.

Heterogeneity in endowments. Heterogeneity in endowments (i.e., $\left.y_{1} \neq y_{0}\right)$ could depict heterogeneity in skills. Even though there is no production side in this paper, $y_{i}$ can be seen as earnings coming from a labour activity. If all agents face the same wage, a low-skilled agent has a lower labour income compared to a high-skilled. In contrast to heterogeneity in preferences, I do not impose restrictions on the distribution of endowments $y_{i}$. Along the paper, I consider two configurations: $y_{0}<y_{1}$ and $y_{0}>y_{1}$. In the first configuration (i.e., $\gamma_{0}<\gamma_{1}$ and $y_{0}<y_{1}$ ), agents 1 with the strongest willingness for wealth accumulation also have the highest labour income in the economy. ${ }^{7}$ In the the second configuration (i.e., $\gamma_{0}<\gamma_{1}$ and $y_{0}>y_{1}$ ), agents 1 with the strongest willingness for wealth accumulation have the lowest labour income in the economy. This last configuration could illustrate an economy in which agents 1 would be an annuitant, i.e., a person mainly living on capital income.

Optimal behaviour. Given an initial level of wealth $w_{i}(0)$, a household $i$ maximizes her utility function (1) with respect to $\left(c_{i}(t), w_{i}(t), s_{i}(t)\right)$ under the following budget and stock constraints:

$$
\begin{aligned}
\dot{w}_{i}(t) & =[\dot{q}(t)+d] s_{i}(t)+y_{i}-c_{i}(t) \\
w_{i}(t) & =q(t) s_{i}(t)
\end{aligned}
$$

Let $r(t)$ be the interest rate of the asset defined as follows:

$$
r(t)=\frac{\dot{q}(t)+d}{q(t)}
$$

Under Assumptions 1 and 2, the optimal behaviour of a household $i$ is summarized by the following Euler equation and transversality condition:

$$
\begin{gathered}
\frac{\dot{c}_{i}(t)}{c_{i}(t)}=\frac{1}{1+\alpha(\varepsilon-1)}\left[r(t)-\rho+\frac{\gamma_{i}}{\alpha} \frac{c_{i}(t)}{w_{i}(t)}+\gamma_{i}(1-\varepsilon) \frac{\dot{w}_{i}(t)}{w_{i}(t)}\right] \\
\lim _{t \rightarrow+\infty} e^{-\rho t} u_{i c}\left(c_{i}(t), w_{i}(t)\right) w_{i}(t)=0
\end{gathered}
$$

\footnotetext{
${ }^{7}$ This case seems consistent with empirical studies on U.S data which show that top income earners have higher propensity to save (see Carroll (2000), Dynan et al. (2004), Kumhof et al. (2015)). In their theoretical model, Kuhmof et al. (2015) suppose that only top earners display wealth preferences. They refer to Bakshi and Chen (1996) in which the preference for wealth is specific to a social-wealth index increasing with the income of the group. In my paper, all agents have preferences for wealth. Nevertheless, this configuration is also in line with Bakshi and Chen (1996).
} 
Since all agents have preferences for wealth, and Inada conditions are satisfied both for consumption and wealth, $s_{i}(t)>0$ is the only solution satisfying the optimal behaviour of the household $i$.

Without preferences for wealth, I get the standard Euler equation found in Lucas (1978) $\left(\gamma_{i}=0\right)$ :

$$
\frac{\dot{c}_{i}(t)}{c_{i}(t)}=\frac{r(t)-\rho}{1+\alpha(\varepsilon-1)}
$$

In this settings, there is no room for expectation-driven asset price fluctuations, and heterogeneity in endowments does not matter. When agents have preferences for wealth, the Euler equation given by Eq. (6) depicts two additional terms compared to Lucas (1978):

$$
\frac{\gamma_{i}}{\alpha} \frac{c_{i}(t)}{w_{i}(t)} \text { and } \gamma_{i}(1-\varepsilon) \frac{\dot{w}_{i}(t)}{w_{i}(t)}
$$

The first term corresponds to the marginal rate of substitution of consumption for wealth, through which the preferences for wealth increase the willingness to delay consumption for the future. It is worth noting that this term will have an impact on the wealth distribution in the long run. Because of it, every agent has an incentive to hold financial assets in the long run. Through the second term, the willingness to postpone consumption is reinforced if wealth and consumption are Edgeworth-complements (i.e., $\varepsilon<1$ ), or dampened if substitutes (i.e., $\varepsilon>1$ ). Interestingly, the second term is at the origin of expectation-driven fluctuations. Indeed, Kamihigashi (2008) considers a separable utility function between consumption and wealth (i.e., $\varepsilon=1$ ), meaning that the second term does not appear in his framework. He shows that the equilibrium is unique, and thus there is no room for expectation-driven fluctuations. This result shows that non-separable utility function is a necessary condition for multiplicity of equilibria, and the second term $\gamma_{i}(1-\varepsilon) \dot{w}_{i}(t) / w_{i}(t)$ is the key ingredient through which expectation-driven fluctuations occur.

\section{Intertemporal equilibrium}

An intertemporal equilibrium is defined as follows:

Definition 1 Under Assumptions 1 and 2, an equilibrium of the economy $E=\left(n, \rho, d,\left(y_{i}\right.\right.$, $\left.\left.u_{i}, s_{i}(0)\right)_{i=0}^{1}\right)$ is an intertemporal path $\left(q(t),\left(s_{i}(t), c_{i}(t)\right)_{i=0}^{1}\right)_{t \geq 0}$ satisfying the optimal behaviour 
of agents (3)-(7) and the equilibrium condition on the asset market:

$$
n_{0} s_{0}(t)+n_{1} s_{1}(t)=1 .
$$

Let $\psi=1+\alpha(\varepsilon-1)$ and $\theta_{i}=\gamma_{i}(1-\varepsilon)$. From Definition 1, an intertemporal equilibrium is a path $\left(q(t), c_{1}(t), s_{1}(t)\right)_{t=0}^{+\infty}$ satisfying the following three-dimensional dynamic system:

$$
\left\{\begin{array}{c}
-\psi \frac{\dot{c_{1}(t)}}{c_{1}(t)}+\left(1+\theta_{1}\right) \frac{\dot{q}(t)}{q(t)}+\theta_{1} \frac{\dot{s_{1}}(t)}{s_{1}(t)}=\rho-\frac{\gamma_{1}}{\alpha} \frac{c_{1}(t)}{q(t) s_{1}(t)}-\frac{d}{q(t)} \\
\psi \frac{n_{1} c_{1}(t)}{d+n y-n_{1} c_{1}(t)} \frac{\dot{c_{1}(t)}}{c_{1}(t)}+\left(1+\theta_{0}\right) \frac{\dot{q}(t)}{q(t)}-\theta_{0} \frac{n_{1} s_{1}(t)}{1-n_{1} s_{1}(t)} \frac{\dot{s_{1}(t)}}{s_{1}(t)} \\
=\rho-\frac{\gamma_{0}}{\alpha} \frac{d+n y-n_{1} c_{1}(t)}{q(t)\left(1-n_{1} s_{1}(t)\right)}-\frac{d}{q(t)} \\
\frac{\dot{s_{1}(t)}}{s_{1}(t)}=\frac{d}{q(t)}+\frac{y_{1}}{q(t) s_{1}(t)}-\frac{c_{1}(t)}{q(t) s_{1}(t)}
\end{array}\right.
$$

where $s_{i}(0)>0$ is given. Note that there are one predetermined variable $s_{1}(t)$ and two nonpredetermined variables $q(t)$ and $c_{1}(t)$.

I can now study the existence and the uniqueness of the steady state, then local dynamic properties of the economy, while emphasizing the role of the heterogeneity both in preferences and in endowments. In order to evaluate the effect of the heterogeneity on the stationary asset price level and on the occurrence of expectation-driven fluctuations, I apply the meanpreserving method. Before starting the analysis of the steady state, I present this method in the next section.

\section{Mean-preserving approach to heterogeneity}

To highlight and understand the role of heterogeneity in preferences and in endowments on the stationary asset price level and local dynamics, I impose a mean-preserving spread of distribution. In other words, I fix the midpoints $\gamma$ and $y$ defined as follows:

$$
\gamma \equiv \frac{n_{0} \gamma_{0}+n_{1} \gamma_{1}}{n} \text { and } y \equiv \frac{n_{0} y_{0}+n_{1} y_{1}}{n}
$$


and I define a measure for each source of heterogeneity:

$$
\begin{aligned}
\sigma_{\gamma} & \equiv \sqrt{\frac{n_{0}}{n}\left(\gamma_{0}-\gamma\right)^{2}+\frac{n_{1}}{n}\left(\gamma_{1}-\gamma\right)^{2}} \\
\sigma_{y} & \equiv \sqrt{\frac{n_{0}}{n}\left(y_{0}-y\right)^{2}+\frac{n_{1}}{n}\left(y_{1}-y\right)^{2}}
\end{aligned}
$$

where $\sigma_{\gamma}$ and $\sigma_{y}$ are respectively the standard deviations of the distribution of weight of wealth in preferences and the standard deviations of the distribution of endowments.

To keep the analysis as simple as possible, I define two heterogeneity parameters, $x$ and $z$, given by $x=\gamma_{1}-\gamma$ and $z=y_{1}-y$. Under Assumption $1, x$ is defined on $\left(0, \gamma n_{0} / n_{1}\right)$. Since I do not impose any restrictions on the distribution of endowments, $z$ is defined on $\left(-y, y n_{0} / n_{1}\right)$. When $y_{1}<y_{0}$, one has $z<0$, and conversely, $z>0$ when $y_{1}>y_{0}$. I can rewrite the standard deviations as functions of $x$ and $z$ :

$$
\begin{aligned}
& \sigma_{\gamma}=x \sqrt{n_{1} / n_{0}}, \forall x \in\left(0, \gamma n_{0} / n_{1}\right) \\
& \sigma_{y}=\left\{\begin{array}{c}
-z \sqrt{n_{1} / n_{0}}, \text { if } y_{1}<y_{0}, \\
z \sqrt{n_{1} / n_{0}}, \text { if } y_{1}>y_{0}
\end{array}\right.
\end{aligned}
$$

Note for future reference that an increase in $z$ in absolute value expresses a raise in the dispersion of endowments $y_{i}$, ceteris paribus.

\section{$5 \quad$ Steady state analysis}

A steady state is an equilibrium where $\dot{s}_{1}(t)=0, \dot{c}_{1}(t)=0, \dot{q}(t)=0$, and $r(t)=r$ for all $t$. From Eqs. (5) and (8)-(11), I deduce that a steady state satisfies the following equations:

$$
\begin{aligned}
r & =\rho-\frac{x+\gamma}{\alpha} \frac{d s_{1}+z+y}{q s_{1}} \\
r & =\rho-\frac{\gamma-x n_{1} / n_{0}}{\alpha} \frac{d s_{0}+y-z n_{1} / n_{0}}{q s_{0}} \\
r & =\frac{d}{q}
\end{aligned}
$$

From Eqs. (8), (17) and (18), I get the distribution of wealth $\left(s_{1}^{*}\right.$ and $\left.s_{0}^{*}\right)$, the asset price level $\left(q^{*}\right)$, and combining with Eq. (19) the interest interest rate $\left(r^{*}\right)$ at the steady state.

Therefore, a steady state is a solution $\left(s_{1}^{*}, q^{*}\right)$ with $s_{1}^{*} \in\left(0,1 / n_{1}\right)$ and $q^{*}>0$ satisfying the 
following system:

$$
\left\{\begin{aligned}
(x+\gamma) \frac{d s_{1}+z+y}{s_{1}} & =\left(\gamma-x n_{1} / n_{0}\right) \frac{d\left(1-n_{1} s_{1}\right)+n_{0}\left(y-z n_{1} / n_{0}\right)}{1-n_{1} s_{1}} \\
q= & \frac{d}{r\left(q, s_{1}\right)} \\
& \text { with } r\left(q, s_{1}\right)=\rho-\frac{\gamma n c+x n\left[d\left(s_{1}-1 / n\right)+z\right] n_{1} / n_{0}}{\alpha n q} \\
& \text { and } \quad n c=d+n y
\end{aligned}\right.
$$

The next proposition proves the existence of a unique steady state bringing the heterogeneity parameters $(x$ and $z)$ out. $^{8}$

Proposition 1 Under Assumption 1 and 2, there exists a unique steady state $\left(s_{1}^{*}, q^{*}\right)$ such that $s_{1}^{*}=s_{1}^{*}(x, z) \in\left(0,1 / n_{1}\right)$ and $q^{*}=q^{*}(x, z)>0$.

Proof. See Appendix 9.1.

The expressions of $s_{1}^{*}(x, z)$ and $q^{*}(x, z)$ are given in Appendix 9.1. Proposition 1 indicates that the stationary asset price level $q^{*}$ and the distribution of wealth given by $s_{1}^{*}\left(s_{0}^{*}=(1-\right.$ $\left.n_{1} s_{1}^{*}\right) / n_{0}$ ) are affected both by the dispersion of endowments $(z)$ and the dispersion of preferences $(x)$. If two economies differ with respect to $x$ and $z$, then they experience different levels of asset prices and different distributions of wealth.

In the following, I first characterize the steady-state wealth distribution, then I describe the stationary asset price level, and the role of heterogeneity in endowment on this latter.

\subsection{Stationary wealth and total income distributions}

Financial wealth and total income are naturally used to rank individuals in a society, and thus provide some insights about social inequalities. This subsection aims to characterize the stationary distributions in wealth and total income.

I define the stationary wealth of an agent $i$ as the real value of assets she holds, i.e., $w_{i}^{*}(x, z)=$ $q^{*}(x, z) s_{i}^{*}(x, z)$, whereas her total income is given by $R_{i}^{*}(x, z)=d s_{i}^{*}(x, z)+y_{i}$. Through the next proposition, this subsection aims to characterize the distribution of wealth and total income within the economy at the steady state.

Proposition 2 Let $\underline{x} \equiv-\frac{\gamma n z}{d+n_{0} y_{1}+n_{1} y_{0}}$ and $\bar{x} \equiv-\frac{\gamma n z}{d}$. Under Assumptions 1 and 2 , the following holds at the steady state:

\footnotetext{
${ }^{8}$ In this paper, the uniqueness of steady state is a direct consequence of the class of preferences I consider, namely homothetic preferences. However, Greenwood-Hercowitz-Huffman preferences $u\left(c_{i}(t)+G_{i}\left(w_{i}(t)\right)\right.$, with $G_{i}^{\prime}()>$.0 and $G^{\prime \prime}()<$.0 , also ensures a unique steady state. Proofs are available upon requests.
} 
1. The wealth distribution is non-degenerate meaning that all agents hold financial assets $s_{i}^{*}(x, z)>0$.

2. Agents 1 hold a greater amount of financial assets than agents 0 (i.e., $s_{1}^{*}(x, z)>s_{0}^{*}(x, z)$ ), if and only if, they have a sufficiently strong willingness for wealth accumulation compared to agents 0 , i.e., $\gamma_{1}>\gamma_{0}+\underline{x} n / n_{0}$ (or, $\left.x>\underline{x}\right)$.

3. Agents 1 are the richest in terms of total income in the economy, if and only if, they have a sufficiently strong willingness for wealth accumulation compared to agents 0, i.e., $\gamma_{1}>\gamma_{0}+\bar{x} n / n_{0}($ or, $x>\bar{x})$.

Proof. See Appendix 9.2.

Proposition 2 shows that all agents in the economy hold a positive share of stock $s_{i}(t)>0$ in contrast to Becker (1980) and Kocherlakota (1992). In infinite-horizon general equilibrium models à la Becker (1980), agents differ with respect to their subjective discount rate and their initial wealth. They face borrowing constraints, but display no preferences for wealth. In such a framework, a household would like to dissave until $s_{i}(t)=0$ as soon as her subjective discount rate $\rho$ is greater than the interest rate $r(t)$. Since the interest rate is given by the most patient, the wealth distribution is degenerate: The most patient agent holds all the financial wealth of the economy. Because of preferences for wealth, all agents accumulate financial assets whatever the interest rate level in this framework. ${ }^{9}$ In infinite-horizon models à la Kocherlakota (1992), agents differ in terms of endowments and initial wealth. They face short-sales constraints, but display no preferences for wealth. Under some conditions, the poor would like to short shell, but they cannot. Hence, they sell until $s_{i}(t)=0$. In my framework, preferences for wealth encourage all agents in the economy to hold financial assets at the steady state. As markets are complete, agents are able to equalize their marginal rate of substitution between wealth and consumption at the steady state.

Note that $x>\underline{x}>\bar{x}$ is always satisfied when agents 1 with with the strongest willingness for wealth accumulation in the economy are the rich in terms of endowments (i.e., $\gamma_{1}>\gamma_{0}$ and $\left.y_{1}>y_{0}\right)$. Proposition 2 provides a theoretical evidence of some stylized facts about the saving behaviour of the rich people observed in the data, in particular why the rich save too much (see Carroll (2000) and Dynan et al. (2004)). ${ }^{10}$

\footnotetext{
${ }^{9}$ Suen (2014) also obtains a non-degenerate distribution of capital in a model with time preference heterogeneity and preferences for wealth.

${ }^{10}$ Admittedly, it partially replicates U.S. data in the sense that a part of American households do not hold financial wealth (see Survey of Consumer Finances (2013)), but I can overcome this issue by adding a third class of agents who do not expresses preferences for wealth. At the steady state, this class of agents holds no wealth (see Appendix 9.3.). Since the dynamics in the neighbourhood of the steady state is driven by the behaviour of agents holding wealth at the steady state, this third class of agents does not affect the dynamics of asset prices.
} 
In the rest of the paper, I focus only on the case when agents 1 are the richest in terms of total income in the economy. To do this, I make the following assumption :

Assumption $3 \gamma_{1}>\gamma_{0}+\bar{x} n / n_{0}$

\subsection{Stationary asset price level}

Eq. (19) indicates that the stationary asset price level is equal to dividends per share deflated by the stationary interest level $r^{*}$, which is equivalent to:

$$
\frac{d}{r^{*}}=d \int_{t}^{+\infty} e^{-r^{*}(s-t)} d s
$$

The right-hand side of Eq. (24) corresponds to the present discounted value of future dividends, which is the definition of the fundamental value of an asset. The following proposition characterizes the asset price level at the steady state.

Proposition 3 Under Assumptions 1- 3, the following holds at the steady state:

1. There is no bubble at the steady state.

2. When $\gamma_{0}=\gamma_{1}$ (i.e., $x=0$ ), the asset price $q^{*}$ does not depend on heterogeneity in endowments, $\sigma_{y}$.

3. When $\gamma_{0}<\gamma_{1}$ (i.e., $x>0$ ):

(a) The asset price is decreasing with heterogeneity in endowements (i.e., a lower $z$ ) when $y_{1}<y_{0}$, and is increasing with heterogeneity in endowements (i.e., a higher $z$ ) when $y_{1}>y_{0}$.

(b) The asset price $q^{*}$ is increasing with heterogeneity in preferences, $\sigma_{\gamma}$, (i.e., with $x$ ).

Proof. See Appendix 9.4.

Proposition 3.1. shows the non-existence of bubbles at the steady state. As underlined by Kamihigashi (2008) and Airaudo (2017) in a representative agent framework with preferences for wealth and a financial asset providing dividends, the presence of positive dividends explains this result. In contrast, Zhou (2015) proves that a bubble on an asset providing no dividends can exist at the steady state. Since I restrict my attention on the occurrence of expectation-driven asset price fluctuations in the neighbourhood of a steady sate, the economy does not exhibit bubbles. 
When agents face same preferences (i.e., $\gamma_{1}=\gamma_{0}$ ), heterogeneity in endowments does not affect the stationary asset price level (Proposition 3.2). I can show from Eqs. (17) and (19) that the asset price is equal to $\bar{q}=d / \rho+(d+n y) \gamma /(\alpha \rho)$, which corresponds to the stationary asset price level found in a representative agent framework. This result relies on the homothetic property of the preferences. Chatterjee (1994) shows that when preferences are homothetic or quasi-homothetic and agents are only heterogeneous in terms of initial wealth, the aggregate dynamics are exactly the same as in the standard optimal growth model with a representative agent. Caselli and Ventura (2000) extend this result to heterogeneity in skills and preferences for public goods.

Interestingly, Propositions 3.2. and 3.3.a. show that heterogeneity in endowments matters only if preferences are heterogeneous. The explanation relies on the fact that I consider preferences for wealth and not for public goods. When preferences are heterogeneous (i.e., $\gamma_{1}>\gamma_{0}$ ), the stationary asset price level decreases with the dispersion of endowment distribution when agents 1 have the smallest endowments in the economy, and increases with the dispersion of endowment distribution otherwise (Proposition 3.3.a).

Economic intuition behind Proposition 3.3.a. Suppose that agents 1 with the strongest willingness for wealth accumulation in the economy are the rich in terms of endowments (i.e., $\gamma_{1}>\gamma_{0}$ and $\left.y_{1}>y_{0}\right)$. An increase in the dispersion of endowment distribution (i.e., $y_{0}$ decreases and $y_{1}$ increases in the same proportions) urges agents 1 to accumulate more wealth, and agents 0 less, since wealth is a normal good. The increase in asset demand of agents 1 is sufficient to counteract the decrease in asset demand of agents 0 . Since the asset supply is fixed, the asset price level increases following an increase in $\sigma_{y}$. I can provide the same rationale for the case $y_{1}<y_{0}$ by considering the reversed mechanism.

Propositions 3.3.b. also shows that the stationary asset price level increases with the dispersion of $\gamma_{i}$ distribution if the willingness for wealth accumulation of agents 1 is sufficiently high compared to agents 0 (i.e., $\left.+\gamma_{1}>\gamma_{0}+\bar{x} n / n_{0}\right)$.

Economic intuition behind Proposition 3.3.b. When $y_{1}>y_{0}$, agents 1 have a higher income compared to agents 0 . An increase in the dispersion of $\gamma_{i}$ (i.e., $\gamma_{1}$ increases and $\gamma_{0}$ decreases in the same proportions) urges agents 1 to accumulate more wealth, and agents 0 less. The increase in asset demand of agents 1, sufficient to counteract the decrease in asset demand of agents 0 , generates a rise in the asset price level. If agents 1 are the poor (i.e., $y_{1}<y_{0}$ ), but their willingness for wealth accumulation is sufficiently high compared to agents 0 (i.e., $\left.+\gamma_{1}>\gamma_{0}+\bar{x} n / n_{0}\right)$, the previous mechanism prevails as well. 


\section{Expectation-driven asset price fluctuations and the role of heterogeneity}

In this paper, I am interested in the existence of asset price fluctuations driven by self-fulfilling changes on agents' expectations without requiring any shock on the fundamentals, i.e., preferences and/or dividends. To do this, I analyse the local dynamic properties of the model, and refer to local indeterminacy concept for the existence of expectation-driven fluctuations. Local indeterminacy means that there exist multiple equilibria with the same initial condition which converge to a steady state.

I $\log$-linearize the 3 -dimensional dynamic system (9)-(11) around the steady state $\left(q^{*}, s_{1}^{*}\right)$ to obtain the characteristic polynomial. As shown in Appendix 9.5., I can derive the trace $T(\varepsilon)$, the sum of the second order principal minor $S(\varepsilon)$ and the determinant $D(\varepsilon)$ of the associated Jacobian matrix as functions of $\varepsilon$. The characteristic polynomial of this economy is given by:

$$
P(\lambda)=\lambda^{3}-T(\varepsilon) \lambda^{2}+S(\varepsilon) \lambda-D(\varepsilon)
$$

Local indeterminacy occurs when the stable manifold has a dimension greater than the number of predetermined variables. Since $s_{1}(t)$ is the only predetermined, the steady state is locally determinate when the Jacobian matrix has zero or one eigenvalue with negative real part, and locally indeterminate when it has at least two eigenvalues with negative real part. The next proposition provides the conditions on the inverse of the intertemporal elasticity of substitution $\varepsilon$ for which local indeterminacy occurs.

Proposition 4 Let $\underline{\varepsilon}(x, z) \equiv 1+\frac{n c}{\gamma n c+x\left[d\left(s_{1}^{*}-1 / n\right)+z\right] n n_{1} / n_{0}}>1$. Under Assumptions 1- 3, the following holds:

1. If $\varepsilon \in(0, \underline{\varepsilon}(x, z))$, the steady state is locally determinate.

2. If $\varepsilon>\underline{\varepsilon}(x, z)$, the steady state is locally indeterminate.

Proof. See Appendix 9.5.

Proposition 4 shows that expectation-driven fluctuations are likely to occur when the inverse of the intertemporal elasticity of substitution $\varepsilon$ is sufficiently high, in particular greater than 1 . This implies that local indeterminacy occurs only if wealth and consumption are Edgeworthsubstitutes (i.e., $u_{c w}<0$ ). Otherwise, the steady state is always determinate.

The literature about MIUF provides a similar result. A necessary condition for local indeterminacy in MIUF model is a negative cross-derivative of the utility function between consumption and money. Nevertheless, a negative cross-derivative is neither empirically plausible (Walsh 
(2010)) nor consistent with the idea that money serves as a medium exchange. In contrast, assuming a negative cross-derivative between wealth and consumption is coherent with the concept of frugality at the root of SOC hypothesis developed by Weber (1905). Furthermore, several studies shed light on the fact that housing and consumption are Edgeworth-substitutes (see Piazzesi, et al. (2007), Yogo (2006), Flavin and Nakagawa (2008)). Since housing wealth is a large component of households' wealth (see Survey of Consumer Finances (2013) for U.S. data), a negative cross-derivative between wealth and consumption would be empirically consistent.

Economic intuition. I provide the mechanisms through which fluctuations driven by selffulfilling changes on expectations occur in the economy. Since aggregate consumption is constant along an equilibrium path, and the economy remains near the steady state, combining Eqs. (9) and (10) gives:

$$
\begin{aligned}
\frac{n_{0}}{n c(t)} & {\left[\frac{\gamma_{1}}{\alpha} \frac{c_{1}(t)}{q(t) s_{1}(t)} c_{1}(t)+\frac{\gamma_{0}}{\alpha} \frac{c_{0}(t)}{q(t) s_{0}(t)} c_{0}(t)\right]=\rho-\frac{\dot{q}(t)+d}{q(t)} } \\
& -\frac{1}{n c(t)}\left\{n_{1} c_{1}(t)\left[\gamma_{1}(1-\varepsilon)\right]+n_{0} c_{0}(t)\left[\gamma_{0}(1-\varepsilon)\right]\right\} \frac{\dot{q}(t)}{q(t)}
\end{aligned}
$$

with $c(t)$ the average consumption, i.e., $c(t)=\left[n_{1} c_{1}(t)+n_{0} c_{0}(t)\right] / n=(d+n y) / n$.

Eq. (26) indicates that the aggregate marginal rate of substitution of consumption for wealth (left-hand side) is equal the opportunity cost of wealth holdings (right-hand side) along an equilibrium path. It is worth noting that a change in asset price level has an ambiguous effect through the opportunity cost when $\varepsilon>1$. When $\varepsilon>\underline{\varepsilon}(x, z)$, which is equivalent to $n_{1} c_{1}(t)\left[1+\gamma_{1}(1-\varepsilon)\right]+n_{0} c_{0}(t)\left[1+\gamma_{0}(1-\varepsilon)\right]<0$, the opportunity cost of holding asset increases following a positive change in asset prices, and decreases otherwise.

Suppose that agents change their expectations at the same time and in the same manner, and they believe that a small drop in the asset price from the stationary level $q^{*}$ occurs. As the consequence of their new beliefs, the opportunity cost of holding asset decreases when $\varepsilon>\underline{\varepsilon}(x, z)$. Eq. (26) can be satisfied only if the marginal rate of substitution decreases. This occurs only if the asset price increases. After a small deviation of the asset price from its stationary level, the economy monotonically converges toward its steady state. Therefore, the resulting new path is an equilibrium. Because there are an infinite number of such paths, the steady state is locally indeterminate, and any change in expectations generates fluctuations.

More interestingly, Proposition 4 also indicates that the critical value $\underline{\varepsilon}$, for which fluctuations are likely to occur, is a function both of heterogeneity in preferences and heterogeneity in endowments $(x$ and $z$ ). This means that heterogeneity plays a role in the emergence of expectation-driven asset price fluctuations. 


\section{The role of heterogeneity on expectation-driven fluctu- ations}

In this section, I investigate the issue of heterogeneity in preferences and endowments on the existence of expectation-driven asset price fluctuations in the neighbourhood of the steady state. Heterogeneity promotes asset price volatility as soon as it enlarges the range of parameter values for which local indeterminacy occurs. If heterogeneity reduces the range of parameter values, then it has stabilizing virtues. The results are twofold: First, heterogeneity in endowments plays a role on the asset price volatility only when agents face different preferences. Second, heterogeneity in preferences and endowments destabilize the economy under some parameter conditions.

First of all, I examine how $\underline{\varepsilon}$ varies in function of $z$ when $\gamma_{0}=\gamma_{1}($ i.e., $x=0)$, then when $\gamma_{0}<\gamma_{1}$ (i.e., $x>0$ ). For a qualitative illustration, see Fig. 1 when $\gamma_{0}=\gamma_{1}$ and Fig. 2 when $\gamma_{0}<\gamma_{1}$. Grey areas correspond local indeterminacy regions for which expectation-driven fluctuations occur.

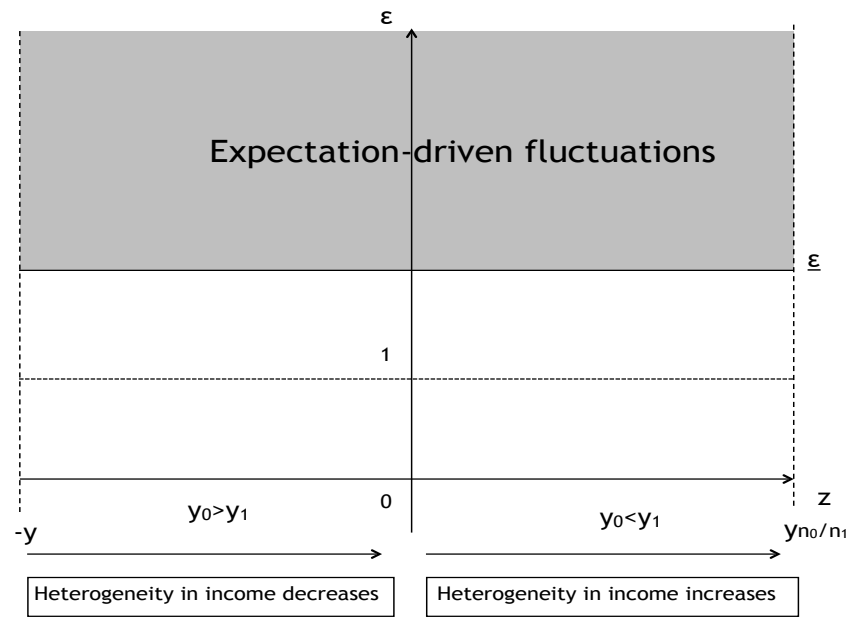

Figure 1: Stabilizing role of heterogeneity in endowments when $\gamma_{0}=\gamma_{1}$

Corollary 1 Under Assumptions 1 and 2, when preferences for wealth are homogeneous ( $x=$ $0)$, heterogeneity in endowments has no impact on the conditions for the existence of local indeterminacy.

When preferences are homogeneous, the critical value $\underline{\varepsilon}$ is given by $1+1 / \gamma$, where $\gamma$ is given by Eq. (12). Therefore, heterogeneity in endowments plays no role in the occurrence of expectationdriven asset price fluctuations. As discussed in Section 5.2., this is due to the homothetic properties of preferences. 


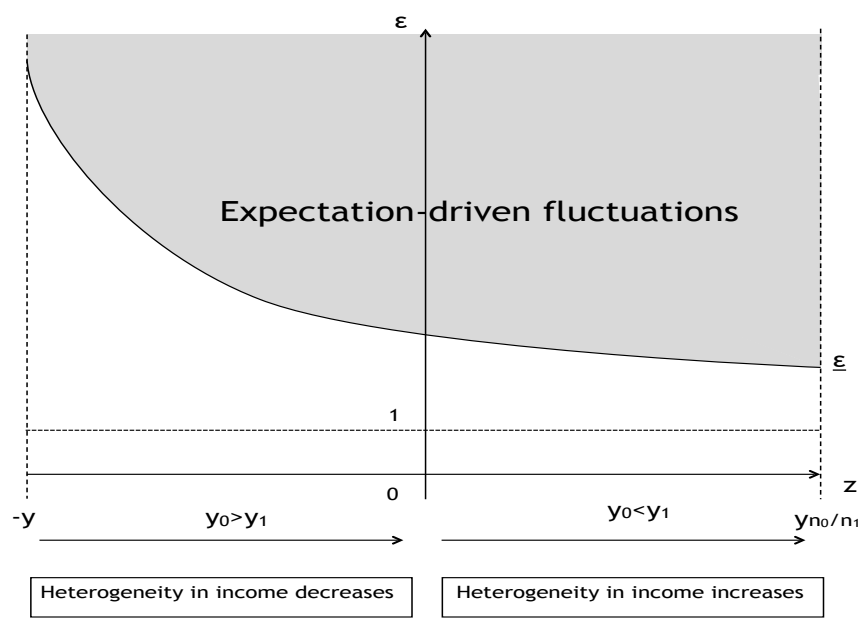

Figure 2: Stabilizing role of heterogeneity in endowments when $\gamma_{0}<\gamma_{1}$

Corollary 2 Under Assumptions 1 and 2, the following holds when $\gamma_{0}<\gamma_{1}$ (i.e., $x>0$ ):

1. When $y_{0}<y_{1}$, an increase in endowment heterogeneity (i.e., a higher $z$ ) destabilizes, by enlarging the range of parameter value for which local indeterminacy occurs.

2. When $y_{0}>y_{1}$, an increase in endowment heterogeneity (i.e., a lower z) stabilizes, by reducing the range of parameter values for which local indeterminacy occurs.

Proof. See Appendix 9.6.

Economic intuition. Recall that a change in asset price level has an ambiguous effect through the opportunity cost when $\varepsilon>1$ (see Eq. (26)), and that local indeterminacy occurs only if $\varepsilon>\varepsilon(x, z)$, which is equivalent to:

$$
n_{1} c_{1}(t)\left[1+\gamma_{1}(1-\varepsilon)\right]+n_{0} c_{0}(t)\left[1+\gamma_{0}(1-\varepsilon)\right]<0
$$

Under Assumption 2, Inequality (27) can be satisfied only if $\left[1+\gamma_{1}(1-\varepsilon)\right]<0$. This implies that local indeterminacy occurs if the effect on the opportunity cost stemming from a change in behaviour of agents 1 dominates.

When $y_{0}>y_{1}$, a rise in the dispersion of endowment distribution dampens the effect stemming from a change in the behaviour of agent 1, and thus prevents the economy from the occurrence of expectation-driven asset price fluctuations. The reverse argument holds when $y_{1}>y_{0}$.

I now examine how $\underline{\varepsilon}$ varies in function of $x$. For a qualitative illustration, see Fig. 3 . 


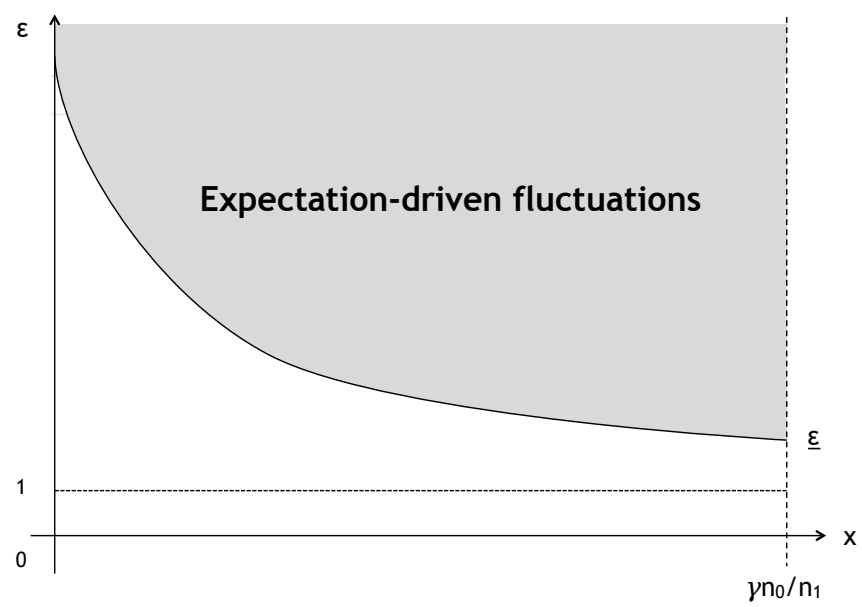

Figure 3: Destabilizing role of heterogeneity in preferences

Corollary 3 Under Assumptions 1-3, an increase in preference heterogeneity (i.e., a higher x) destabilizes, by enlarging the range of parameter value for which local indeterminacy.

Proof. See Appendix 9.6.

Economic intuition. When agents 1 have a sufficiently strong willingness for wealth accumulation compared to agents 0 , i.e., $\gamma_{1}>\gamma_{0}+\bar{x} n / n_{0}$, a rise in the dispersion of preference distribution $\gamma_{i}$ strengthens the effect on the opportunity cost stemming from a change in the behaviour of agent 1 , and thus promotes the occurrence of expectation-driven asset price fluctuations in the economy.

\section{Concluding remarks}

In this paper, I address the following question: What are the implications of heterogeneity in terms of preferences and endowments on the occurrence of asset price fluctuations driven by self-fulfilling changes on expectations under the SOC hypothesis?

I provide a theoretical approach by adding two ingredients to the pure exchange economy developed by Lucas (1978). The first ingredient is heterogeneity - in preferences, in endowments and in initial wealth. The second ingredient is preferences for wealth, which captures the SOC hypothesis originated from Max Weber (1905).

These two novelties induce a non-degenerate wealth distribution at the steady state, meaning that all agents hold financial assets. The existence of preferences for wealth matters for the occurrence of expectation-driven fluctuations in asset prices. Investigating the role of he- 
terogeneity, this paper shows that heterogeneity in preferences is a key element. Heterogeneity in endowments can destabilize by promoting the occurrence of expectation-driven asset price fluctuations in the economy only when preferences are heterogeneous.

By providing new insights into the role of heterogeneity on asset price volatility, this framework can be used to investigate how a redistribution policy, like capital income taxation, should be implemented to rule out excessive asset price fluctuations, and stabilize the economy as a whole.

\section{$9 \quad$ Appendix}

\subsection{Proof of Proposition 1}

A steady state $\left(s_{1}^{*}, q^{*}\right)$ is a solution of $q_{1}\left(s_{1}\right)=q_{0}\left(s_{1}\right)$, with:

$$
\left\{\begin{array}{l}
q_{1}\left(s_{1}\right)=\frac{x+\gamma}{\alpha \rho} \frac{d s_{1}+y+z}{s_{1}}+\frac{d}{\rho} \\
q_{0}\left(s_{1}\right)=\frac{\gamma-x n_{1} / n_{0}}{\alpha \rho} \frac{d\left(1-n_{1} s_{1}\right)+n_{0}\left(y-z n_{1} / n_{0}\right)}{1-n_{1} s_{1}}+\frac{d}{\rho}
\end{array}\right.
$$

There exists at least one value $s_{1}^{*} \in\left(0,1 / n_{1}\right)$ such that $q_{1}\left(s_{1}^{*}\right)=q_{0}\left(s_{1}^{*}\right)$. Recall that $x+\gamma=$ $\gamma_{1}>0$, and $y+z=y_{1}>0$. As $q_{1}\left(s_{1}\right)>0 \forall s_{1} \in\left(0,1 / n_{1}\right)$, I deduce that $q^{*}=q_{1}\left(s_{1}^{*}\right)>0$.

Since $q_{1}\left(s_{1}\right)$ is strictly decreasing on $\left(0,1 / n_{1}\right)$ and $q_{0}\left(s_{1}\right)$ is strictly increasing on $\left(0,1 / n_{1}\right)$, the solution $\left(q^{*}, s_{1}^{*}\right)$ is unique.

\subsection{Proof of Proposition 2}

Proposition 2.1 is a direct consequence of Proposition 1. Let us now prove Proposition 2.2. ${ }^{11}$ Note that $s_{1}^{*}>s_{0}^{*}$ is equivalent to $s_{1}^{*}>1 / n$. One has $q_{1}^{\prime}\left(s_{1}\right)<0, q_{0}^{\prime}\left(s_{1}\right)>0$ and $q_{1}\left(s_{1}^{*}\right)=q_{0}\left(s_{1}^{*}\right)$, where $q_{1}\left(s_{1}\right)$ and $q_{0}\left(s_{1}\right)$ are respectively given by (27) and (28). Hence, $s_{1}^{*}>1 / n$ if and only if $q_{1}(1 / n)>q_{0}(1 / n)$. This inequality is equivalent to $x>-\gamma n z /\left(d+n_{0} y_{1}+n_{1} y_{0}\right) \equiv \underline{x}$. As $x=\gamma_{1}-\gamma=\left(\gamma_{1}-\gamma_{0}\right) n_{0} / n$, then $x>\underline{x}$ is equivalent to $\gamma_{1}>\gamma_{0}+\underline{x} n / n_{0}$. Proposition 2.2. follows. I now prove Proposition 2.3. Note that $d s_{1}^{*}+y_{1}>d s_{0}^{*}+y_{0}$ is equivalent to $s_{1}^{*}>1 / n-z / d$. $s_{1}^{*}>1 / n-z / d$ if and only if $q_{1}(1 / n-z / d)>q_{0}(1 / n-z / d)$. This inequality is equivalent to $x>-\gamma n z / d \equiv \bar{x}$. As $x=\gamma_{1}-\gamma=\left(\gamma_{1}-\gamma_{0}\right) n_{0} / n$, then $x>\bar{x}$ is equivalent to $\gamma_{1}>\gamma_{0}+\bar{x} n / n_{0}$. Proposition 2.3. follows.

\footnotetext{
${ }^{11}$ For simplicity, the arguments of the functions are omitted.
} 


\subsection{Three classes of agents in the economy}

Suppose that there are three classes of agents in the economy. Two classes display preferences for wealth $\left(\gamma_{i}>0\right)$ and the third one not $\left(\gamma_{j}=0\right.$ with $\left.i \neq j\right)$. The Euler equation associated with an agent without preferences for wealth is given by:

$$
\begin{aligned}
& \frac{\dot{c_{j}}(t)}{c_{j}(t)} \geq \frac{r(t)-\rho}{1+\alpha(\varepsilon-1)} \\
& s_{j}(t) \geq 0
\end{aligned}
$$

The Euler equation associated with an agent displaying preferences for wealth is given by:

$$
\begin{aligned}
\frac{\dot{c}_{i}(t)}{c_{i}(t)} \geq \frac{r(t)-\rho}{1+\alpha(\varepsilon-1)}+\frac{\gamma_{i} c_{i}(t) /\left(w_{i}(t)\right)-\gamma_{i}(\varepsilon-1) \dot{w}_{i}(t) / w_{i}(t)}{1+\alpha(\varepsilon-1)} \\
s_{i}(t) \geq 0
\end{aligned}
$$

At the steady state, an equilibrium is such that:

$$
r=\rho-\frac{\gamma_{i} c_{i}}{w_{i}}<\rho
$$

Therefore, agents without preferences for wealth hold no assets at the steady state.

\subsection{Proof of Proposition 3}

I first prove Proposition 3.1 claiming that the asset price is equal to its fundamental value at the steady state.

Let $r(t)$ be an interest rate, $q(t)$ the asset price in terms of consumption good at time $t$ and $d$ the dividends in in terms of consumption good generated by the asset. The no-arbitrage condition that governs the evolution of the asset price is given by:

$$
q(t)=\frac{\dot{q}(t)+d}{r(t)}
$$

Solving Eq. (29) by iterating forward, I obtain:

$$
q(t)=\int_{t}^{+\infty} e^{\int_{t}^{s}-r(i) d i} d \mathrm{~d} s+e^{\int_{t}^{+\infty}-r(i) d i} q(+\infty)
$$

The first term depicts the fundamental value of the asset $v(t)$, while the second term is the 
definition of a bubble $b(t)$ :

$$
\begin{aligned}
& v(t)=\int_{t}^{+\infty} e^{\int_{t}^{s}-r(i) d i} d \mathrm{~d} s \\
& b(t)=e^{\int_{t}^{+\infty}-r(i) d i} q(+\infty)
\end{aligned}
$$

At the steady state, $q(t)=q^{*}$ and $r(t)=r^{*}$. Therefore, from (31), I have

$$
v(t)=d \int_{t}^{+\infty} e^{-r^{*}(s-t)} \mathrm{d} s=\frac{d}{r^{*}} \equiv v^{*}
$$

Combining Eq. (29) evaluated at the steady state with (33), one has:

$$
q^{*}=\frac{d}{r^{*}}=v^{*}
$$

The asset price is equal to its fundamental component at the steady state.

I now prove Propositions 3.2 and 3.3 which addresses the effect of heterogeneity on the asset price level $q^{*}$ at the steady state. In a first step, I study the effect of heterogeneity in endowments (Proposition 3.2. and 3.3.a). Then in a second step, I study the effect of heterogeneity in preferences (Proposition 3.3.b).

Recall that a steady state is a solution $\left(s_{1}^{*}, q^{*}\right)$ with $s_{1}^{*} \in\left(0,1 / n_{1}\right)$ and $q^{*}>0$ satisfying the following system:

$$
\left\{\begin{aligned}
(x+\gamma) \frac{d s_{1}+z+y}{s_{1}} & =\left(\gamma-x n_{1} / n_{0}\right) \frac{d\left(1-n_{1} s_{1}\right)+n_{0}\left(y-z n_{1} / n_{0}\right)}{1-n_{1} s_{1}} \\
q= & \frac{d}{r\left(q, s_{1}\right)} \\
& \text { with } r\left(q, s_{1}\right)=\rho-\frac{\gamma n c+x n\left[d\left(s_{1}-1 / n\right)+z\right] n_{1} / n_{0}}{\alpha n q} \\
& \text { and } \quad n c=d+n y
\end{aligned}\right.
$$

Using Eqs. (36) and (37), I get:

$$
q^{*}=\frac{d n}{\rho}+\frac{\gamma n c+x\left[d\left(s_{1}^{*}-1 / n\right)+z\right] n n_{1} / n_{0}}{\rho \alpha}
$$

Therefore,

$$
\frac{\partial q^{*}}{\partial \sigma_{y}}=\frac{n n_{1}}{n_{0} \rho \alpha} x\left(1+d \frac{\partial s_{1}^{*}}{\partial z}\right) \frac{\partial z}{\partial \sigma_{y}}
$$


Note that when $x=0$, one has $\frac{\partial q^{*}}{\partial \sigma_{y}}=0$. Proposition 3.2. follows. When $x>0$, I have to determine the signs of $\frac{\partial s_{1}^{*}}{\partial z}$ and $\frac{\partial z}{\partial \sigma_{y}}$.

Applying the implicit theorem function to Eq. (35), one has under Assumptions 1 and 2:

$$
\frac{\partial s_{1}^{*}}{\partial z}=\frac{n_{1} \gamma_{0} /\left(n_{0} s_{0}^{*}\right)+\gamma_{1} / s_{1}^{*}}{\gamma_{1} y_{1} / s_{1}^{* 2}+n_{1} \gamma_{0} y_{0} /\left(n_{0} s_{0}^{* 2}\right)}>0
$$

Recall that $z=y_{1}-y$ with $n y=n_{1} y_{1}+n_{0} y_{0}$ and

$$
\sigma_{y}=\left\{\begin{array}{c}
-z \sqrt{n_{1} / n_{0}}, \text { if } y_{1}<y_{0} \\
z \sqrt{n_{1} / n_{0}}, \text { if } y_{1}>y_{0}
\end{array}\right.
$$

Since $\partial z / \partial \sigma_{y} \leq 0$ when $y_{1} \leq y_{0}$, and $\partial z / \partial \sigma_{y} \geq 0$ when $y_{1} \geq y_{0}$, Propositions 3.3.a follows.

I now study the effect of heterogeneity in preferences (Proposition 3.3.b). Using Eq. (39), I get:

$$
\frac{\partial q^{*}}{\partial \sigma_{x}}=\frac{n n_{1}}{n_{0} \rho \alpha}\left[d\left(s_{1}^{*}-\frac{1}{n}\right)+z+x d \frac{\partial s_{1}^{*}}{\partial x}\right] \frac{\partial x}{\partial \sigma_{x}}
$$

Applying the implicit theorem function to Eq. (35), one has under Assumptions 1 and 2:

$$
\frac{\partial s_{1}^{*}}{\partial x}=\gamma \frac{n y s_{1}^{*}}{x} \frac{s_{1}^{*}-y_{1} / n y}{s_{1}^{* 2} x d n n_{1} / n_{0}+(x+\gamma) y_{1}}
$$

Note that $\partial s_{1}^{*} / \partial x>0$ is equivalent to $s_{1}^{*}>y_{1} /(n y)$. One has $q_{1}^{\prime}\left(s_{1}\right)<0, q_{0}^{\prime}\left(s_{1}\right)>0$ and $q_{1}\left(s_{1}^{*}\right)=q_{0}\left(s_{1}^{*}\right)$, where $q_{1}\left(s_{1}\right)$ and $q_{0}\left(s_{1}\right)$ are respectively given by $(27)$ and (28). Hence, $s_{1}^{*}>$ $y_{1} /(n y)$ if and only if $q_{1}\left(y_{1} /(n y)\right)>q_{0}\left(y_{1} /(n y)\right)$. This inequality is equivalent to

$$
x\left[\frac{d y_{1} y_{0}}{n y^{2}}+\frac{y_{1} n_{1}}{y n_{0}}\left(y \frac{n_{0}}{n_{1}}-z\right)\right]>0
$$

As $z<y n_{0} / n_{1}$, Inequality (45) is always satisfied. Hence, $\partial s_{1}^{*} / \partial x>0$ is always satisfied. Furthermore, under Assumption 3, one has $d\left(s_{1}^{*}-\frac{1}{n}\right)+z>0$. Therefore, under Assumptions $1-3:$

$$
\frac{n n_{1}}{n_{0} \rho \alpha}\left[d\left(s_{1}^{*}-\frac{1}{n}\right)+z+x d \frac{\partial s_{1}^{*}}{\partial x}\right]>0
$$

Recall that $x=\gamma_{1}-\gamma$ with $n \gamma=n_{1} \gamma_{1}+n_{0} \gamma_{0}$ and $\sigma_{\gamma}=x \sqrt{n_{1} / n_{0}}$. Since $\partial x / \partial \sigma_{\gamma} \geq 0$ under Assumption 1, Propositions 3.3.b follows. 


\subsection{Proof of Proposition 4}

\subsubsection{Linearized dynamic system}

To conduct the analysis, I log-linearize the dynamic system (9)-(11) around the steady state $\left(s_{1}^{*}, q^{*}\right)$ with respect to $\left(s_{1 t}, q_{t}, c_{1 t}\right)$, and define $\hat{x}=\log \left(x / x^{*}\right)$. Let $\psi=1+\alpha(\varepsilon-1)$ and $\theta_{i}=\gamma_{i}(1-\varepsilon)$, I obtain $^{12}$ :

$$
\begin{aligned}
& \left(\begin{array}{ccc}
-\psi & 1+\theta_{1} & \theta_{1} \\
\psi n_{1} c_{1}^{*} /\left(n_{0} c_{0}^{*}\right) & 1+\theta_{0} & -\theta_{1} n_{1} c_{1}^{*} /\left(n_{0} c_{0}^{*}\right) \\
0 & 0 & 1
\end{array}\right)\left(\begin{array}{c}
\dot{\hat{c}}_{1} \\
\dot{\hat{q}} \\
\hat{\hat{s}}_{1}
\end{array}\right) \\
& =\left(\begin{array}{ccc}
-\left(\rho-d / q^{*}\right) & \rho & \left(\rho-d / q^{*}\right) \\
\left(\rho-d / q^{*}\right) n_{1} c_{1}^{*} /\left(n_{0} c_{0}^{*}\right) & \rho & -\left(\rho-d / q^{*}\right) \gamma_{1} n_{1} c_{1}^{*} /\left(\gamma_{0} n_{0} c_{0}^{*}\right) \\
-\left(\rho-d / q^{*}\right) \alpha / \gamma_{1} & 0 & d / q^{*}
\end{array}\right) \times\left(\begin{array}{c}
\hat{c}_{1} \\
\hat{q} \\
\hat{s}_{1}
\end{array}\right)
\end{aligned}
$$

with $c_{1}^{*}=d s_{1}^{*}+y+z$ and $c_{0}^{*}=d\left(1 / n_{0}-n_{1} s_{1}^{*} / n_{0}\right)+y-z n_{1} / n_{0}$.

\subsubsection{The Characteristic Polynomial $P(\lambda)$}

The characteristic polynomial of this economy is given by:

$$
P(\lambda)=\lambda^{3}-T(\varepsilon) \lambda^{2}+S(\varepsilon) \lambda-D(\varepsilon)
$$

where

$$
\begin{aligned}
T(\varepsilon) & =\rho \frac{\varepsilon-\bar{\varepsilon}}{\varepsilon-\underline{\varepsilon}} \\
D(\varepsilon) & =\frac{D_{1}(\varepsilon)}{\varepsilon-\underline{\varepsilon}} \\
D(\varepsilon)-S(\varepsilon) T(\varepsilon) & =\frac{\delta_{0}(\varepsilon)}{(\varepsilon-\underline{\varepsilon})^{2}}\left[\delta_{1}(\bar{\varepsilon}-\underline{\varepsilon})+\delta_{2}(1-\varepsilon)(\bar{\varepsilon}-\varepsilon)\right]-\delta_{3} \frac{\bar{\varepsilon}-\varepsilon}{(\varepsilon-\underline{\varepsilon})^{2}}
\end{aligned}
$$

\footnotetext{
${ }^{12}$ For simplicity, the arguments of the functions are omitted.
} 
where under Assumptions 1-2,

$$
\begin{aligned}
\underline{\varepsilon} & =1+\frac{n c}{\gamma_{1} n_{1} c_{1}^{*}+\gamma_{0} n_{0} c_{O}^{*}}>1 \\
\bar{\varepsilon} & =1+2 \frac{n c}{\gamma_{1} n_{1} c_{1}^{*}+\gamma_{0} n_{0} c_{O}^{*}}>\underline{\varepsilon} \\
D_{1} & =\frac{\rho}{1-\alpha(1-\varepsilon)} \frac{1}{\alpha q^{*}}\left(n_{1} c_{1}^{*} \frac{y_{0}}{q^{*} s_{0}^{*}}+n_{0} c_{0}^{*} \frac{y_{1}}{q^{*} s_{1}^{*}}\right)>0, \forall \varepsilon>0 \\
\delta_{0}(\varepsilon) & =\rho \frac{\rho-d / q^{*}}{1-\alpha(1-\varepsilon)} \frac{1}{\gamma_{1} \gamma_{0}} \frac{s_{1}^{*}}{2 \gamma_{1} c_{1}^{*}}>0 \forall \varepsilon>0 \\
\delta_{1} & =\gamma_{1} \gamma_{0}\left(n_{1} c_{1}^{*} \frac{y_{0}}{q^{*} s_{0}^{*}}+n_{0} c_{0}^{*} \frac{y_{1}}{q^{*} s_{1}^{*}}\right)>0 \\
\delta_{2} & =\gamma_{1} \gamma_{0}\left(\gamma_{1} n_{1} c_{1}^{*} \frac{y_{0}}{q^{*} s_{0}^{*}}+\gamma_{0} n_{0} c_{0}^{*} \frac{y_{1}}{q^{*} s_{1}^{*}}\right)>0 \\
\delta_{3} & =\rho^{3} \frac{n c}{c_{1}^{*}} \frac{s_{1}^{*}}{\gamma_{1}}>0
\end{aligned}
$$

with $c=\left(n_{1} c_{1}^{*}+n_{0} c_{0}^{*}\right) / n=d / n+y$.

\subsubsection{Proof of Proposition 4}

Recall that

- For $T(\varepsilon)<0$, if $D(\varepsilon)<0$ and $D(\varepsilon)>S(\varepsilon) T(\varepsilon)$, there are three eigenvalues with negative real parts;

- For $T(\varepsilon)<0$ and $D(\varepsilon)>0$ or for $T(\varepsilon)>0, D(\varepsilon)>0$ and $D(\varepsilon)>S(\varepsilon) T(\varepsilon)$, there are two eigenvalues with negative real parts;

- For $T(\varepsilon)<0$, if $D(\varepsilon)<0$ and $D(\varepsilon)<S(\varepsilon) T(\varepsilon)$ or, for $T(\varepsilon)>0$, if $D(\varepsilon)<0$, there is one eigenvalue with negative real part;

- For $T(\varepsilon)>0$, if $D(\varepsilon)>0$ and $D(\varepsilon)<S(\varepsilon) T(\varepsilon)$, there is no eigenvalue with negative real part.

By analysing Eqs. (48) - (50), one has:

- If $\varepsilon<\underline{\varepsilon}$, then $T(\varepsilon)>0$ and $D(\varepsilon)<0$, thus there is one eigenvalue with negative real parts.

- If $\varepsilon \in(\underline{\varepsilon}, \bar{\varepsilon})$, then $T(\varepsilon)<0$ and $D(\varepsilon)>0$, thus there are two eigenvalues with negative real parts.

- If $\varepsilon>\bar{\varepsilon}$, then $T(\varepsilon)>0, D(\varepsilon)>0$ and $D(\varepsilon)>S(\varepsilon) T(\varepsilon)$, thus there are two eigenvalues with negative real parts. 
Following Blanchard-Kahn (1980) conditions, I conclude that:

- Local determinacy when there are zero or one eigenvalue with negative real part;

- Local indeterminacy when there are at least two eigenvalues with negative real part.

Since $\gamma_{1}=\gamma+x, \gamma_{0}=\gamma-x n_{1} / n_{0}, n c=n_{1} c_{1}^{*}(x, z)+n_{0} c_{0}^{*}(x, z)=d+n y$ and $c_{1}^{*}(x, z)=$ $d s_{1}^{*}(x, z)+y+z, \underline{\varepsilon}$ can be rewritten as follows:

$$
\underline{\varepsilon}=1+\frac{n c}{\gamma n c+x\left[d\left(s_{1}^{*}(x, z)-1 / n\right)+z\right] n n_{1} / n_{0}}
$$

Proposition 4 follows.

\subsection{Proofs of Corollaries 2 and 3}

Recall that:

$$
\begin{aligned}
q^{*} & =\frac{d n}{\rho}+\frac{\gamma n c+x\left[d\left(s_{1}^{*}(x, z)-1 / n\right)+z\right] n n_{1} / n_{0}}{\rho \alpha} \\
\underline{\varepsilon} & =1+\frac{n c}{\gamma n c+x\left[d\left(s_{1}^{*}(x, z)-1 / n\right)+z\right] n n_{1} / n_{0}}
\end{aligned}
$$

From Eqs. (59) and (60), I deduce that

$$
\begin{aligned}
& \operatorname{sign} \frac{\partial \underline{\varepsilon}}{\partial z}=\operatorname{sign}-\frac{\partial q^{*}}{\partial z} \\
& \operatorname{sign} \frac{\partial \underline{\varepsilon}}{\partial x}=\operatorname{sign}-\frac{\partial q^{*}}{\partial x}
\end{aligned}
$$

Corollaries 2 and 3 follow Proposition 3.

\section{References}

[1] Airaudo, M. (2017), "Complex stock price dynamics and recurrent bubbles under the spirit of capitalism", Economic Theory 47, 47-73.

[2] Aiyagari, S. R. (1994), "Uninsured Idiosyncratic Risks and Aggregate Saving", Quaterly Journal of Economics 109, 659-684.

[3] Atkinson, A.B., Piketty, T. and E. Saez (2011), "Top incomes in the long run of history", Journal of Economic Literature 49, 3-71.

[4] Bakshi, G.S. and Z. Chen (1996), "The spirit of capitalism and stock market prices", The American Economic Review 86, 133-157.

[5] Becker, R.A. (1980), "On the long-run steady state in a simple dynamic model of equilibrium with heterogeneous households", Quarterly Journal of Economics 95, 375-382. 
[6] Becker, R.A. (2006), "Equilibrium dynamics with many agents", in: T.M. Rose-Anne Dana, Cuong Le Van and K. Nishimura, eds., Handbook on Optimal Growth 1. Discrete Time, Springer Berlin Heidelberg, 385-442.

[7] Bewley, T. (1977), "The permanent income hypothesis: A theoretical formulation", Journal of Economic Theory 16, 252-292.

[8] Breeden, D.T. (1979), "An intertemporal asset pricing model with stochastic consumption and investment opportunities", Journal of Financial Economics 7, 265-296.

[9] Boileau, M. and R. Braeu (2007), "The spirit of capitalism, asset returns, and the business cycles", Macroeconomic Dynamics 11, 214-230.

[10] Campbell, J. Y., and J. H. Cochrane (1999), "By force of habit: a consumption-based explanation of aggregate stock market behavior", Journal of Political Economy 107, 205251.

[11] Carroll, C. (2000), "Why Do the Rich Save So Much?", In Does Atlas Shrug? The Economic Consequences of Taxing the Rich, Harvard University Press.

[12] Caselli, F. and J., Ventura (2000), "A Representative Consumer Theory of Distribution," American Economic Review 90, 909-926.

[13] Chatterjee, S. (1994), "Transitional dynamics and the distribution of wealth in a neoclassical growth model," Journal of Public Economics, 54, 97-119.

[14] Dynan, K., Skinner, J. and Zeldes, S. (2004), "Do the rich save more?", Journal of Political Economy 112, 397-444.

[15] Flavin, M. and S. Nakagawa (2008) "A model of housing in the presence of adjument costs: A structural interpretation of habit persistence", American Economic Review 98, 474-495.

[16] Gali, J. (1994) "Keeping Up with the Joneses: Consumption Externalities, Portfolio Choice, and Asset Prices," Journal of Money, Credit and Banking 26, 1-8.

[17] Gong, L. and H-F. Zou. (2002). "Direct Preferences for Wealth, the Risk Premium Puzzle, Growth, and Policy Effectiveness," Journal of Economic Dynamics and Control, 26, 271302.

[18] Huang, K. and J., Werner (2004), "Implementing Arrow-Debreu equilibria by trading infinitely-lived securities", Economic Theory 24, 603-622.

[19] Kamihigashi, T. (2008), "The spirit of capitalism, stock market bubbles and output fluctuations ", International Journal of Economic Theory 4, 3-28.

[20] Keynes, J.M. (1919), The Economic Consequences of the Peace.

[21] Kocherlakota, N. R. (1992), "Bubbles and constraints on debt accumulation", Journal of Economic Theory 57, 245-256.

[22] Kumhof, M., Rancière R. and P. Winant (2015), "Inequality, Leverage and Crises", American Economic Review 105, 1217-1245.

[23] Le Van, C., N.S. Pham and Y. Vailakis (2015) "Financial asset bubble with heterogeneous agents and endogenous borrowing constraints ", Working Paper.

[24] Lucas, R.E. (1978), "Asset Prices in an Exchange Economy", Econometrica 46, 1429-1445.

[25] Marx, K. (1867), Capital. 
[26] Matsuyama, K. (1990), "Sunspot equilibria (rational bubbles) in a model of money-in-theutility function", Journal of Monetary Economics 25, 137-144.

[27] Obstfeld, M. (1984), "Multiple stable equilibria in an optimizing perfect foresight model", Econometrica 52, 223-228.

[28] Piazzesi, M., M. Schneider, and S. Tuzel (2007), "Housing, Consumption and Asset Pricing", Journal of Financial Economics 83, 531569.

[29] Rajan, R. (2010), Fault Lines, Princeton Univerity Press, Princeton.

[30] Saez E. and S. Stantcheva (2016), "A Simpler Theory of Optimal Capital Taxations", NBER, Working Paper No. 22664.

[31] Santos, M. S., and M. Woodford (1997), "Rational asset pricing bubbles", Econometrica 65, 19-57.

[32] Shiller, R. J. (1981), "Do stock prices move too much to be justified by subsequent changes in dividends?", American Economic Review 71, 421-436.

[33] Shiller, R. J. (2015), Irrational Exuberance, Princeton University Press, Princeton.

[34] Smith, W.T. (2001), "How does the spirit of capitalism affect stock market prices?", Review of Financial Studies 14, 1215-1232.

[35] Stiglitz, J. E. (1970), "A consumption-oriented theory of the demand for financial assets and the term structure of interest rates", Review of Economic Studies 37, 321-351

[36] Suen, R. M. H. (2014) "Time preference and the distributions of wealth and income", Economic Inquiry 52, 364-381.

[37] Survey of Consumer Finances (2013).

[38] Walsh, C. E. (2010), Monetary Theory and Policy, Third Edition, MIT Press Books, The MIT Press.

[39] Weber, M. (1905), "The protestant ethic and the spirit of capitalism", Charles Scribners Sons, New York.

[40] Yogo, M. (2006) "A consumption-based explanation of expected stock returns", Journal of Finance 61, 539580 .

[41] Zou, H-F. (1994), "The Spirit of Capitalism and Long-Run Growth", European Journal of Political Economy 10, 279-293.

[42] Zou, H-F. (1995), "The spirit of capitalism and savings behavior", Journal of Economic Behavior and Organization 28, 131-145.

[43] Zhou, G. (2015), "The Spirit Of Capitalism And Rational Bubbles", Macoreconomic Dynamics 20, 1432-1457. 